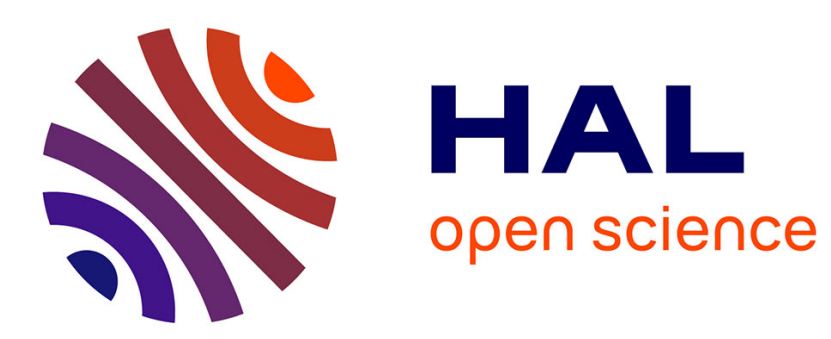

\title{
Fraude sans précédent à la présidentielle iranienne de juin 2009

\author{
Marie Ladier-Fouladi
}

\section{To cite this version:}

Marie Ladier-Fouladi. Fraude sans précédent à la présidentielle iranienne de juin 2009. Outre-terre. Revue européenne de géopolitique, 2011, n²8, 10.3917/oute.028.0249 hal-03209917

\section{HAL Id: hal-03209917 https://hal.science/hal-03209917}

Submitted on 27 Apr 2021

HAL is a multi-disciplinary open access archive for the deposit and dissemination of scientific research documents, whether they are published or not. The documents may come from teaching and research institutions in France or abroad, or from public or private research centers.
L'archive ouverte pluridisciplinaire HAL, est destinée au dépôt et à la diffusion de documents scientifiques de niveau recherche, publiés ou non, émanant des établissements d'enseignement et de recherche français ou étrangers, des laboratoires publics ou privés. 


\title{
FRAUDE SANS PRÉCÉDENT À LA PRÉSIDENTIELLE IRANIENNE DE JUIN 2009
}

\author{
Marie Ladier-Fouladi
}

Outre-terre | Outre-Terre

$2011 / 2-n^{\circ} 28$
pages 249 à 272

ISSN 1636-3671

Article disponible en ligne à l'adresse:

http://www.cairn.info/revue-outre-terre-2011-2-page-249.htm

Pour citer cet article :

Ladier-Fouladi Marie , «Fraude sans précédent à la présidentielle iranienne de juin 2009 »,

Outre-Terre, 2011/2 n²8, p. 249-272. DOI : 10.3917/oute.028.0249

Distribution électronique Cairn.info pour Outre-terre.

(c) Outre-terre. Tous droits réservés pour tous pays.

La reproduction ou représentation de cet article, notamment par photocopie, n'est autorisée que dans les limites des conditions générales d'utilisation du site ou, le cas échéant, des conditions générales de la licence souscrite par votre établissement. Toute autre reproduction ou représentation, en tout ou partie, sous quelque forme et de quelque manière que ce soit, est interdite sauf accord préalable et écrit de l'éditeur, en dehors des cas prévus par la législation en vigueur en France. II est précisé que son stockage dans une base de données est également interdit. 


\section{Fraude sans précédent à la présidentielle iranienne de juin 2009}

Marie Ladier-Fouladi ${ }^{1}$

\section{INTRODUCTION}

L'annonce précipitée des résultats de la présidentielle du 12 juin 2009 et de la victoire de Mahmoud Ahmadinejâd, félicité aussitôt par le Guide suprême, l'ayatollah Khâmene'i, avant même que le Conseil de surveillance de la Constitution, seule instance habilitée à valider les scrutins, confirme la réélection du président sortant, a provoqué un tollé en Iran. Dès le 13 juin, plusieurs centaines de milliers d'électeurs scandant "où est mon vote? " ont spontanément manifesté dans les rues des grandes villes iraniennes, notamment à Téhéran, pour contester ces résultats. Au cours des jours suivants, alors que les protestations postélectorales ne cessaient de s'amplifier, les autorités continuaient à insister sur la validité du scrutin. Le 15 juin, Mahmoud Ahmadinejâd lui-même déclare devant des milliers de ses partisans réunis au centre de Téhéran que les élections iraniennes, dont celle qu'il venait de remporter, étaient « les plus propres » du monde. Le Guide suprême qui conduit exceptionnellement la prière le vendredi 19 juin intervient une nouvelle fois pour réfuter toute possibilité de tricherie. Et de s'interroger lors de son sermon sur le nombre de voix qui séparaient Mahmoud Ahmadinejâd de Mir-Hoseyn Moussavi : "Si l'écart était de cent mille, de cinq cent mille ou d'un million, on pourrait se dire qu'il y a bien eu fraude. Mais comment aurait-on pu trafiquer onze millions de voix ? ". Si les autorités pouvaient en effet rejeter avec pareille véhémence toute accusation de fraude, c'est que l'État islamique qui a derrière lui trente années d'organisation de scrutins politiques ne s'est jamais doté des mécanismes nécessaires à la transparence des scrutins. Les hauts responsables de l'État étaient en conséquence assurés que les candidats malheureux à la présidentielle ne pourraient pas démontrer, preuves solides à l'appui, la fraude et les truquages. Ainsi, lorsque pour calmer les manifestations de rue le Conseil de surveillance de la Constitution a condescendu à recompter un échantillon de $10 \%$ des bulletins en présence de journalistes iraniens il ne courait aucun risque. C'est sans surprise que le recomptage n'a pas apporté d'éléments tangibles invalidant l'élection, le même Conseil entérinant définitivement les résultats du scrutin et la réélection de Mahmoud Ahmadinejâd le 29 juin.

1. CNRS - CEPED/Paris V-Descartes. 
Or, la comparaison des cartes électorales des quatre candidats révèle des anomalies extravagantes qui remettent en question la validité des résultats de la présidentielle de 2009. En supposant que les comportements électoraux maintiennent une relative stabilité au cours du temps, une concordance entre les votes et la géographie électorale de ces quatre candidats devrait s'avérer. Il n'en a rien été. La fraude et le truquage ont d'abord été effectués à l'échelle des circonscriptions puis parachevés dans le «Bureau national des élections » du ministère de l'Intérieur.

\section{LA PROCÉDURE ÉLECTORALE}

En République islamique, le jeu électoral sert aux différentes factions politiques qui évaluent leur poids et veulent accéder au pouvoir afin de préserver dans une logique clientéliste l'intérêt des groupes d'influence qu'elles représentent. D'où une procédure électorale particulièrement opaque et ambiguë ${ }^{2}$ qui offre une marge considérable de manœuvre à la falsification et au truquage.

Conformément à la loi électorale et à la Constitution de la République islamique, le Conseil de surveillance de la Constitution, institution non-élective ${ }^{3}$, et le ministère de l'Intérieur ont la charge respective de superviser et d'organiser les élections. Depuis 1979, les dirigeants ont sans cesse procédé à des manœuvres contestables afin de contrôler la procédure électorale et de s'assurer du résultat des scrutins. Ainsi en 1995, le quatrième Parlement, formé pour l'essentiel de représentants de la faction de droite conservatrice, a amendé l'article 3 de la loi électorale sur les législatives de façon à attribuer les pleins pouvoirs au Conseil de surveillance dans le contrôle du scrutin : «La surveillance des élections législatives revient au Conseil de surveillance. Il s'agit d'une surveillance juste et générale de l'ensemble du processus et des procédures de l'élection en cours ». Depuis lors, la notion de "surveillance juste ", vague et insaisissable, a servi notamment à invalider les candidats des factions opposées à la droite dont faisaient partie la plupart des membres de ce même Conseil. Ce dernier n'hésitant pas non plus à annuler sous divers prétextes plusieurs centaines de milliers de bulletins de votes, en particulier dans les grandes circonscriptions comme celle de Téhéran, lorsque les résultats des urnes ne lui conviennent pas ${ }^{4}$.

L'une des principales caractéristiques de la procédure électorale en Iran est la présélection par élimination des candidats avant même que les campagnes électorales ne soient ouvertes. Cela soulève la question de la restriction apportée au choix des électeurs et celle de la représentativité effective des élus à l'issue de chaque élection. Mais ces interrogations ne préoccupent pas des autorités qui défendent avec ferveur

\footnotetext{
2. Cf. M. Ladier-Fouladi, Iran Un monde de paradoxes, Nantes, l'Atalante, coll. Comme un accordéon, 2009.

3. Ce Conseil comprend douze membres, dont six clercs jurisconsultes, nommés par le Guide suprême et six juristes proposés par le chef de l'appareil judiciaire - lui-même nommé par le Guide suprême - et élus par le Parlement. 4. Exemple des législatives de 2000 : le Conseil de surveillance a invalidé 720000 bulletins de votes dans la circonscription de Téhéran, soit près de $25 \%$ des suffrages exprimés, afin que 'Ali-Akbar Hâshemi-Rafsanjâni passe du 30, une position déshonorante pour l'ancien président de la République, au $20^{\circledR}$ rang.
} 
un système pour qui l'islamité du système prime sur son républicanisme. Ce qui leur importe en premier lieu, c'est pour des raisons politiques évidentes la participation électorale. Car celle-ci apparaît lors de chaque élection comme un enjeu de première importance dans la mesure où c'est à travers elle que le régime cherche à renouveler sa légitimité. Tous les efforts, et parfois même les concessions, sont destinés à encourager l'électorat à voter. Il faut d'ailleurs interpréter le taux de participation des électeurs proclamé par le ministère de l'Intérieur avec beaucoup de précaution. D'autant que ni les listes électorales ni en conséquence la carte d'électeur n'existent en Iran. Les électeurs munis de leur livret d'identité peuvent voter dans la circonscription ${ }^{5}$ de leur choix. Le responsable du bureau de vote appose alors sur le dernier feuillet du livret de l'électeur un tampon avec la date et la dénomination du scrutin ; on s'assure que la personne ne votera pas une seconde fois en marquant son index à l'encre indélébile.

Lâge minimum du droit de vote est en manière générale fixé à seize ans, mais le législateur décide au dernier moment selon l'élection et les enjeux du scrutin de le relever ou de le rabaisser ${ }^{6}$. Faute de listes électorales, le taux de participation est évalué de manière approximative. Le ministère rapporte en effet le nombre total des bulletins de votes exprimés au nombre estimé ${ }^{7}$ de la population en âge légal de voter. Précisons qu'il n'existe aucun moyen permettant de vérifier les statistiques relatives aux bulletins exprimés et que le ministère de l'Intérieur a tendance à sous-estimer systématiquement le nombre d'électeurs potentiels afin de gonfler le taux de participation (tableau 1).

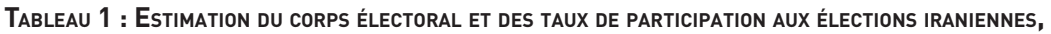
2005-2009 ${ }^{8}$

\begin{tabular}{|c|c|c|c|c|c|}
\hline \multirow{2}{*}{ Type d'élection } & \multirow{2}{*}{$\begin{array}{l}\text { Âge mini- } \\
\text { mum du droit } \\
\text { de vote }\end{array}$} & \multicolumn{2}{|c|}{ Nombre d'électeurs (en millions) } & \multicolumn{2}{|c|}{ Taux de participation } \\
\hline & & $\begin{array}{l}\text { Estimation du mi- } \\
\text { nistère de l'Intérieur }\end{array}$ & $\begin{array}{l}\text { Estimation } \\
\text { de l'auteur }\end{array}$ & $\begin{array}{l}\text { Estimation du mi- } \\
\text { nistère de l'Intérieur }\end{array}$ & $\begin{array}{l}\text { Estimation } \\
\text { de l'auteur }{ }^{8}\end{array}$ \\
\hline $\begin{array}{l}\text { Présidentielles } \\
\text { de juin } 2005\end{array}$ & 15 ans & 46,7 & 50,0 & $62,8 \% *$ & $59,2 \% *$ \\
\hline $\begin{array}{l}\text { Municipales de } \\
\text { décembre } 2006\end{array}$ & 15 ans & 46,0 & 51,5 & $60,0 \%$ & $50,0 \%$ \\
\hline $\begin{array}{l}\text { Législatives } \\
\text { mars-avril } 2008\end{array}$ & 18 ans & 43,8 & 49,5 & $60,0 \% *$ & $48,0 \% *$ \\
\hline $\begin{array}{l}\text { Présidentielle } \\
\text { de juin } 2009\end{array}$ & 18 ans & 46,2 & 51,3 & $85,0 \%$ & $76,0 \%$ \\
\hline
\end{tabular}

* Estimations relatives au premier tour du scrutin.

5. Les circonscriptions correspondent plus au moins aux limites des départements, mais il se peut qu'une circonscription comprenne parfois plusieurs départements. Ces dernières années, le ministère de l'Intérieur présentait les résultats des votes par circonscription, sans distinguer entre les zones urbaines et rurales.

6. Il fut relevé à 17 ans lors des législatives de 2000 , rabaissé à 15 ans à l'occasion de la présidentielle de 2005 et de nouveau relevé à 18 ans pour les législatives de 2008 et la présidentielle de 2009.

7. Il s'agit d'une extrapolation par rapport aux résultats des derniers recensements.

8. Ces estimations sont fondées sur une extrapolation des résultats des recensements de 1996 et de 2006 au moyen des taux d'accroissement intercensitaire. Le nombre estimé des immigrés Afghans, qui n’ont pas le droit de vote, a naturellement été pris en compte dans ce calcul. 
En dépit d'une procédure électorale extrêmement compliquée et opaque qui permettait de multiplier les manœuvres en sa faveur lors de la présidentielle de 2009, Mahmoud Ahmadinejâd, inquiet de l'issue de la bataille électorale, a cru devoir mettre en place des dispositifs supplémentaires pour renforcer le contrôle du processus du scrutin et par là orienter même les résultats à sa guise. Dès le lendemain des législatives de 2008, le président qui était mécontent des résultats avait remercié le ministre de l'Intérieur, pourtant un proche, pour le remplacer par l'un de ses lieutenants ; en mars 2009, il avait nommé l'un de ses fidèles à la tête du "Bureau national des élections " de ce même ministère. En octobre 2008, il avait incorporé avec l'approbation du Guide 4000 nouveaux pâsdârân (Gardiens de la révolution) et basiji (volontaires) dans le corps des hâdiyâne syâsi (guides politiques) institué en 2003. Cette entité qui comprenait dès lors 12000 pâsdârân et basiji avait officiellement pour mission d'encourager les électeurs à participer aux élections, mais elle était officieusement chargée d'inciter les électeurs à voter pour le candidat que l'aile radicale des fondamentalistes, à savoir les pro-Ahmadinejâd, avait choisi de soutenir. L'ensemble de ces dispositifs constituant un puissant levier qui devait normalement assurer Mahmoud Ahmadinejâd du succès électoral.

\section{L'AFFRONTEMENT ÉLECTORAL DES FACTIONS}

L'alliance stratégique conclue entre divers courants issus de la faction des fondamentalistes à l'occasion du second tour des présidentielles de 2005 qui avait conduit à la victoire de Mahmoud Ahmadinejâd ne dura pas longtemps. À peine quelques mois après l'entrée en fonction de ce dernier les dissensions entre fondamentalistes pro- ou anti-Ahmadinejâd minaient à nouveau la scène politique. Désaccords et divergences éclatèrent au grand jour à l'occasion des municipales de décembre 2006 ? Ce premier scrutin depuis l'élection d'Ahmadinejâd représentait un enjeu politique important à l'échelle nationale. Il s'agissait en quelque sorte d'un test pour évaluer la popularité du président tout en offrant une opportunité tant aux adversaires fondamentalistes de celui-ci qu'aux réformateurs et aux modérés de mesurer une capacité de mobilisation autour de leurs candidats, tout comme de redéfinir du même coup les rapports de force avec le clan d'Ahmadinejâd. Or, les adversaires fondamentalistes d' Ahmadinejâd n'allaient pas parvenir à faire liste commune contre lui ; il y eut trois listes séparées : celle de Mahmoud Ahmadinejâd ou "La bonne odeur de servir », constituée de ses proches; la "Coalition des fondamentalistes » plus connue sous le nom de liste (Mohammad-Bâqer Qâlibâf (le rival malheureux d'Ahmadinejâd au premier tour des présidentielles de 2005), comprenant neuf organisations politiques dont certaines de tendance clairement intégriste ; enfin les « Partisans de

9. Pour une présentation détaillée de ce scrutin, cf. Marie Ladier-Fouladi, 2009, Iran Un monde de paradoxes, op. cit. 
la Voie de l'Imam et du Guide " regroupant quatorze formations politiques parmi les plus traditionalistes. Quant aux réformateurs, les quatre principales organisations politiques s'étaient réunies au sein de la "Coalition des réformateurs".

Lors de ces premières élections organisées sous la présidence de Mahmoud Ahmadinejâd, la confusion fut à son comble. La cacophonie produite par les proclamations divergentes du ministère de l'Intérieur et du Conseil de surveillance embrouillant encore situation. Alors que les résultats tombaient au compte-gouttes, les fondamentalistes de la liste de Qâlibâf et les réformateurs criaient les uns et les autres victoire. Les premiers comme les seconds cherchaient à attirer exclusivement l'attention des journalistes occidentaux sur les résultats de Téhéran dont les enjeux étaient sans nul doute de taille. Après un décompte des votes pour le conseil municipal de la capitale qui dura curieusement 6 jours, la liste de Qâlibâf était arrivée en tête avec neuf élus ; suivait celle des réformateurs avec quatre élus; arrivait enfin celle d'Ahmadinejâd avec seulement deux élus. Les résultats complets de cette élection n’ont jamais été communiqués, que ce fût par le gouvernement ou par les factions en compétition. Une source réformatrice ${ }^{10}$ accordant sur 267 élus des chefs-lieux des provinces $54 \%$ aux fondamentalistes, $28 \%$ aux réformateurs et $18 \%$ à des indépendants. La liste de Mahmoud Ahmadinejâd, comptabilisée avec les élus fondamentalistes, représentait $28 \%$ du total fondamentaliste.

Le scrutin municipal avait bien mis en évidence l'échec de la stratégie adoptée par le président qui avait besoin d'une alliance solide chez les fondamentalistes pour remporter les élections suivantes. À leur tour, les deux autres courants fondamentalistes qui avaient selon toute vraisemblance totalisé près de $39 \%$ des voix exprimées avaient pu constater les limites de leur capacité de mobilisation. Certes, l'addition des voix fondamentalistes avait permis à la faction de gagner, mais cette victoire demeurait relative. Les fondamentalistes avaient eu l'ambition de barrer la route aux réformateurs, mais leur division avait ouvert à ceux-ci un espace politique puisqu'ils recueillaient près de $30 \%$ des voix. Les premiers avaient beau disposer de tous les moyens de contrôle de la procédure électorale, force était d'admettre qu'ils n'étaient pas à l'abri d'un vote sanction. Revigorés non pas par leur performance mais par les dissensions des fondamentalistes, les réformateurs, pour leur part, allaient chercher à s'organiser de façon à améliorer leurs positions lors de l'élection suivante.

Les fondamentalistes sont manifestement restés en panne de cohésion. Les ambitions personnelles et les conflits d'intérêts prévalant. À l'approche des législatives de 2008, ces rivalités atteignirent un paroxysme, la faction se présentant divisée en deux listes. Compte tenu des enjeux politiques d'importance que ce scrutin représentait ${ }^{11}$, les fondamentalistes allaient cependant mettre en ouvre un puissant arsenal de moyens afin d'assurer une large victoire à leurs candidats.

10. Site Internet d'information proche des réformateurs mis en ligne à l'occasion des élections municipales, <www.sarnevesht3.com/tahlil-mara-ost-entekh.htm>

11. Cf. Marie Ladier-Fouladi, «La face cachée des législatives iraniennes de 2008 », La Vie des /dées, 2009, <www.laviedesidees.fr/La-face-cachee-des-legislatives.html> 
4954 candidats aux 290 sièges du Parlement - dont il faut soustraire les cinq sièges réservés aux minorités religieuses - réussirent l'examen préliminaire du ministère de l'Intérieur et du Conseil de surveillance pour entrer dans la course. Un grand nombre d'entre eux, issus d'associations et d'organisations politiques locales ou nationales, s'étaient fédérés au sein de larges coalitions. Alors que des candidats qui se déclaraient "indépendants " avaient créé eux aussi à l'échelle nationale leur "Coalition des candidats indépendants du pays ".

La compétition électorale apparaissait néanmoins circonscrite aux quatre principales coalitions qui devaient selon toutes les prévisions se partager les sièges : le "Front uni des fondamentalistes " de Mahmoud Ahmadinejâd et la "Coalition élargie des fondamentalistes ", soutenue par les partisans d'Ali Lârijâni (lui aussi rival malheureux d'Ahmadinejâd au premier tour des présidentielles de 2005) et de Mohammad-Bâqer Qâlibâf; la "Coalition des réformateurs", soutenue notamment par les proches de Mohammad Khâtami et des partisans de Mehdi Karoubi ( autre rival malheureux de Mahmoud Ahmadinejâd au premier tour des présidentielles de 2005) ${ }^{12}$; enfin le « Parti de la modération et du développement " derrière 'Ali-Akbar Hâshemi-Rafsanjâni ${ }^{13}$.

Comme aucun camp n'avait la certitude de l'emporter, les deux coalitions fondamentalistes n'hésitèrent pas, l'une comme l'autre, à s'allier dès le premier tour avec ses adversaires réformateurs ou modérés pour éviter un revers électoral. À l'inverse, les réformateurs, de s'allier avec une partie des fondamentalistes, montraient qu'ils étaient capables de toutes les compromissions pour faire un retour sur la scène politique, quitte à compromettre l'idée même de réforme. En fin de compte, la répartition des candidats sur toutes ces alliances jeta la confusion dans l'esprit d'électeurs qui ne parvenaient plus à distinguer les opinions entre elles.

Au lendemain du scrutin, les quatre coalitions allaient crier victoire. Or, la réalité était plus complexe à décrire, car de nombreux candidats étaient présents sur plusieurs listes à la fois, et en raison d'une multitude de candidats "indépendants ". Sur les 282 élus, 71 soit $25 \%$ étaient " indépendants " et 82 soit $29 \%$ figuraient sur deux, voire trois listes. Dans la mesure où ces élus « multi-investis » ne s'étaient pas situés clairement non plus que positionnés politiquement, chaque coalition les décomptait à son avantage. Le Front uni n'avait emporté que 72 sièges sous sa propre étiquette, la Coalition élargie 30, la Coalition des réformateurs 22 sièges et les modérés 5 . En somme, sur les 282 députés élus ou réélus, 153 étaient politiquement inclassables.

Ni le Front uni ni la Coalition élargie ne l'avaient emporté. Au regard des moyens considérables dont ils disposaient leurs résultats restaient médiocres. C'est

12. Cette coalition était considérée comme le principal adversaire de la faction fondamentaliste; raison pour laquelle les candidatures de nombreuses personnalités influentes figurant sur la liste et désireuses de concourir dans les grandes circonscriptions du pays (Téhéran, Ispahan, Chiraz ou Mashhad) furent rejetées par le Conseil de surveillance.

13. C'est certainement son influence qui a valu à cette formation de fraîche date de pouvoir participer à la compétition électorale et de se hisser parmi les trois premiers acteurs du scrutin. 
finalement grâce à la victoire des 42 candidats présents sur les deux listes que les fondamentalistes, toutes tendances confondues, parvinrent à remporter 144 sièges, soit $50 \%$ du total. Pour dominer l'assemblée, les deux groupes fondamentalistes devaient néanmoins non seulement s'entendre, mais également former des alliances avec les élus inclassables. La victoire des fondamentalistes donc été très relative et discutable dans ses réalités arithmétiques.

Soulignons deux points cruciaux. Le premier est relatif au succès des candidats "indépendants ". Ces 71 élus qui étaient à peu près aussi nombreux que ceux du Front uni et faisaient plus du double de ceux de la Coalition élargie apparaissaient du même coup comme les principaux rivaux potentiels des fondamentalistes. Dans 25 provinces sur 30, on comptait au moins un élu "indépendant ", leur nombre culminant à 7 dans la province d'Azerbaïdjan occidental (au Nord-Ouest) et à 6 dans chacune des provinces d'Ispahan (Centre), de Fârs (Centre-Sud) et de Téhéran (Centre), toutes trois particulièrement importantes du point de vue des enjeux économiques, sociaux et politiques. La géographie complexe du vote en faveur des indépendants traduisait une répartition d'Ouest en Est et du Nord au Sud, sur toutes les provinces sauf cinq. Il semble que l'électorat ait justement saisi l'occasion d'exprimer son mécontentement en apportant ses voix à ces candidats. D’ailleurs : même si un certain nombre de candidats "indépendants " pouvaient bien sûr être proches des fondamentalistes ou à l'inverse des réformateurs, ils n'avaient pas été investis par ces factions et les électeurs ont voté pour eux en tant qu' "indépendants ». Le succès électoral de ces derniers symbolisant l'échec de toutes les factions au pouvoir et un rejet par bon nombre d'électeurs du système politique iranien. Cela d'autant que, pour contester ce même système ou s'en désolidariser, plus de la moitié des électeurs du premier tour et une majorité écrasante d'entre eux au second tour ne se sont pas rendus aux urnes.

Le second point concerne le score médiocre de la coalition du Front uni même si ses 72 élus représentent des circonscriptions parmi les plus importantes politiquement comme Téhéran, Mashhad (Nord-Est) ou Chiraz (Centre-Sud). La stratégie du Front uni était assez simple. En faisant éliminer autant que possible réformateurs et modérés lors de la présélection par le Conseil de surveillance, il pouvait ensuite se retourner massivement contre la Coalition élargie et l'emporter arithmétiquement comme symboliquement en s'attachant en particulier aux circonscriptions majeures. Les votes en faveur du Front uni se concentraient dès lors sur les régions allant, très schématiquement, de l'Est vers le Centre. Mais il faut préciser que selon toute vraisemblance cette " réussite " ne fut possible que moyennant des truquages, comme en témoignent les contestations formées par les chefs de file réformateurs à propos de Téhéran au lendemain du premier tour du scrutin. Il apparaissait que la coalition fondamentaliste soutenue par Ahmadinejâd n'avait pu s'imposer comme la première force politique qu'en recourant à des manœuvres contestables et frauduleuses.

Le scrutin de 2008 mettait en évidence la fragilité des deux factions fondamentalistes et leur incapacité à obtenir l'adhésion de l'électorat. Sans l'aide substantielle 
des institutions électives et non-électives de l'État islamique, elles n'auraient même pas pu atteindre ce médiocre succès électoral.

C'est sur cette toile de fond que va se jouer la bataille présidentielle de juin.

\section{LE PREMIER TOUR DES PRÉSIDENTIELLES DE 2005}

\section{LA CARTE ÉLECTORALE DES FONDAMENTALISTES}

Lors des présidentielles de $2005^{14}$, la faction des fondamentalistes était représentée par trois candidats qui avaient derrière eux une carrière plus ou moins longue au sein des Pâsdârân : Mahmoud Ahmadinejâd, Ali Lârijâni et Mohammad-Bâqer Qâlibâf ${ }^{15}$. La concurrence entre ces derniers renvoyant à la lutte que se livraient les principales forces politiques de la faction, ces dernières visant à modifier par ce scrutin les rapports de force.

C'est Mahmoud Ahmadinejâd qui créa la surprise. En obtenant 20 \% des voix exprimées (soit 5,7 millions de votes), il allait se qualifier pour le second tour. Alors que personne n'aurait parié sur semblable résultat. D’autant qu'il avait mené une campagne modeste sans beaucoup d'affiches ou de tracts publicitaires alors qu'il était peu connu. "Il a avancé phares éteints ", devait déclarer après coup son directeur de la communication. Les votes exprimés en sa faveur étaient passablement concentrés sur le Centre et l'Est ${ }^{16}$. Il arrivait en tête dans neuf provinces dont les plus importantes étaient Semnân (Nord) d'où il est originaire, Téhéran (Centre-Nord), Markazî (Centre), Ispahan (Centre-Sud) et Yazd (Centre-Sud). Il réalisait en revanche un très mauvais score dans les départements des provinces du Nord-Ouest où il avait occupé des fonctions de sous-gouverneur puis de préfet au début des années 1990. Autrement dit : les seuls électeurs qui pouvaient juger sur pièces n’avaient guère apprécié son bilan et s'étaient refusés à lui apporter leurs suffrages. La carte électorale illustre en les zones où M. Ahmadinejâd avait pu mobiliser les réseaux locaux, formés en lien direct avec le développement des activités économiques et militaires des Pâsdârân, en sa faveur (cf. carte 1).

À leur tour, les deux autres candidats fondamentalistes avaient bénéficié du soutien des mêmes types de réseaux dans les régions du Nord-Est, du Centre-Sud et dans une partie des régions du Nord et du Nord-Ouest. Laddition des voix recueillies par ces fondamentalistes - 11,5 millions de votes, soit $40,4 \%$ des bulletins exprimés - correspondait aux zones dans lesquelles l'influence des réseaux militaro-

\footnotetext{
14. Rappelons que sur un peu plus de mille postulants à la candidature pour la course présidentielle de 2005, le Conseil de surveillance $n$ 'en avait validé que onze dont pour finir sept seulement étaient entrés en lice : trois fondamentalistes, deux réformateurs, un proche supposé des réformateurs et un modéré.

15. Pour une présentation plus détaillée des présidentielles de 2005, cf. M. Ladier-Fouladi, Iran Un monde de paradoxes, op. cit.

16. Notre géographie électorale des candidats est fondée sur les statistiques mises en ligne sur le site web du ministère iranien de l'Intérieur. Faute de fonds de carte numérisé correspondant aux 336 départements de 2006, les données ont été agrégées à partir du découpage par département de 1996, soit pour 254 départements.
} 
financiers des Pâsdârân paraissait déterminante pour la réussite électorale de cette faction (cf. carte 2).

Les fondamentalistes avaient déjà effectué des avancées considérables dans les zones au préalable investies par leurs prédécesseurs à l'occasion de la présidentielle de 2001. Il s'agissait principalement des régions développées situées au Nord-Est, Nord, Centre et dans une partie du Sud. Mais les votes en faveur des trois candidats fondamentalistes ne correspondaient pas aux caractéristiques socioconomiques et démographiques de cet électorat régional. Étant donné l'attachement profond aux valeurs islamiques et traditionnelles des fondamentalistes, on se serait attendu à ce que ces derniers recherchent plutôt des suffrages dans les régions où dominent les comportements traditionnels. Or, ils réalisèrent leur meilleurs scores dans les départements où le niveau de fécondité est généralement moins élevé, la proportion des familles élargies moins forte et enfin l'écart de scolarité entre garçons et filles âgés de 6-14 ans, faible, nul, voire négatif, donc favorable aux filles ${ }^{17}$.

Le fait que les activités civiles et militaires des Pâsdârân eussent été toujours très importantes dans ces régions les mieux loties n'était pas étranger à ces résultats. Les chefs des Pasdârân qui soutenaient officieusement la faction fondamentaliste avaient efficacement mobilisé les réseaux de soutien, notamment par l'intermédiaire des basiji et bien sûr du corps des "guides politiques ". En outre, des fondations semi-étatiques dirigées par les fondamentalistes, telles le "Bureau d'aide de l'imam Khomeyni " ou la "Fondation des martyrs " qui assistent des milliers de familles dans ces régions avaient sans doute appelé à voter «fondamentaliste ». Les imams de la Prière du vendredi qui représentent personnellement le Guide dans les provinces, proches donc des fondamentalistes, constituaient également une force mobilisatrice dans ce vivier électoral que sont les mosquées. Fruit d'un effort initié en 2001, les progrès électoraux des trois candidats témoignaient de la redoutable efficacité de ces réseaux.

\section{LA PERMANENCE DES VOTES RÉFORMATEUR ET MODÉRÉ}

À l'instar des fondamentalistes, les réformateurs étaient divisés et furent en définitive représentés par deux candidats : Mehdi Karoubi et Mostafa Mo in, avec également un invité surprise en la personne d'Ali-Akbar Hâshemi- Rafsanjâni. Alors qu'il s'était rangé durant les sept années précédant ce scrutin du côté des fondamentalistes pour entraver la progression des réformateurs, l'ancien président se voulait au-dessus des factions, homme du consensus et du compromis. Venait enfin le candidat indépendant Mohsen Mehralizadeh, proche des réformateurs dès lors qu'il avait été ministre de Mohammad Khâtami.

17. Cf. Marie Ladier-Fouladi, «Le système familial et la politique en Iran », in A. Kian-Thiébaut, M. Ladier-Fouladi (éd.), Famille et mutations sociopolitiques: l'approche culturaliste à l'épreuve, Maison des sciences de l'homme, Colloquium, 2005, p. 40-69. 
La campagne de Mehdi Karoubi, ex-président du parlement de 2000 à 2004, fut essentiellement marquée par sa promesse d'accorder une aide financière mensuelle de 500000 rials (près de 50 euros 2005) à tous les Iraniens âgés de 18 ans et plus. Un engagement populiste qui ramenait les citoyens à un statut de "sujets assistés " mais avait séduit l'électorat de 11 provinces périphériques qui le placèrent en tête : le Sud, le Sud-Ouest, l'Ouest, le Nord-Ouest et le Nord-Est, des territoires considérées comme peu développés et pauvres, selon le Centre statistique d'Iran. Ces régions avaient déjà apporté massivement leurs suffrages à Khâtami en 2001. Karoubi puisant donc surtout dans le réservoir réformateur. Avec un peu plus de 5 millions de votes, $17,6 \%$ des voix exprimées, il arriva en troisième position... ${ }^{18}$ (cf. carte 3 ).

Les deux principales formations politiques réformatrices avaient investi Mostafa Mo'in ; en partie pour attirer les jeunes, notamment des étudiants avec lesquels ce dernier s'était solidarisé en démissionnant de son poste de ministre des Sciences, de la Recherche et de la Technologie en $1999{ }^{19}$. Mo'in n'obtint cependant pas plus de 3,7 millions de votes, $15,5 \%$ des voix exprimées et n'arriva en tête que dans une seule province, le Sistan \& Baloutchistan (Sud-Est du pays). Lélectorat des départements périphériques des Sud-Est, Sud, Nord-Ouest et Ouest, déjà acquis à Khâtami en 1997 et en 2001, lui avait apporté ses suffrages. L'échec s'explique ici par l'impréparation du candidat et par une moindre visibilité à côté de Rafsanjâni et Karoubi considérés par les électeurs comme proches des réformateurs.

Mohsen Mehralizadeh, pour sa part, originaire d'Azerbaïdjan et turcophone, arriva en tête dans les départements peuplés de turcophones des trois provinces situées au Nord-Ouest du pays. Ces provinces qui étaient aussi terre d'élection pour les réformateurs dans la mesure où Mohammad Khâtami y avait recueilli tous les suffrages en 2001. Avec ses 1,2 millions de votes, 4,5\% des voix, Mehralizadeh privait en réalité Mo'in des voix qui auraient pu changer l'issue du premier tour.

Bien que la candidature de Rafsanjâni fût soutenue par deux formations politiques qui avaient fait autrefois partie de la coalition des réformateurs - ce qui pouvait lui valoir la bienveillance de l'électorat réformateur -, il était également en mesure de gagner les faveurs d'un certain nombre de groupes et forces politiques relevant de la faction fondamentaliste. Son électorat était dispersé à l'instar de sa position politique " centriste ». Arrivé en tête dans les trois provinces de Kermân (Sud), Zanjân (Nord) et Gilân (Nord) qui avaient massivement voté Khâtami en 2001, Rafsanjâni réalisa aussi de très bons scores dans des départements situés au Centre, au Nord et

\footnotetext{
18. Il fut le seul candidat à contester publiquement les résultats dès le lendemain du premier tour. Pour rentrer dans le rang sur invitation implicite et discrète du Guide et de certains membres du Conseil de surveillance à se taire et à accepter son échec.

19. En juillet 1999, la protestation estudiantine organisée par le Bureau de la consolidation de l'unité lla plus grande structure iraniennel contre la fermeture d'un quotidien proche des réformateurs s'était transformée en émeute à la suite d'une intervention armée dans la cité universitaire de Téhéran. Ce mouvement qui dura cinq jours fut sévèrement réprimé par les basiji et assimilés aux ordres du Guide suprême. Comme le gouvernement de Mohammad Khâtami n'avait pas condamné l'extrême violence exercée contre les étudiants, son ministre de l'enseignement supérieur et plusieurs doyens et enseignants des universités démissionnèrent en signe de protestation.
} 
au Nord-Est considérés comme marqués par l'influence fondamentaliste, mais aussi dans ceux du Sud, du Sud-Ouest, du Nord-Ouest et de l'Est, des régions où tant l'électorat réformateur que celui des fondamentalistes le considéraient comme sien.

Ce que ses adversaires redoutaient se produisit : avec un peu plus de 6 millions de votes soit $22 \%$ des voix exprimés, 'Ali-Akbar Hâshemi-Rafsanjâni arriva en tête du premier tour des présidentielles de 2005.

Léchec des réformateurs pouvait largement s'expliquer par leur mauvaise appréciation de la complexité du scrutin, conjuguée à un excès de confiance manifeste qui les avait conduits à se présenter divisés. Et ils n'avaient pas réussi à mobiliser leur électorat dont la majorité écrasante se trouvait dans les régions périphériques.

Il ne faudrait pas néanmoins conclure hâtivement à la mutation de la géographie électorale des réformateurs. En ce printemps 2005, le vote en faveur de l'un ou l'autre des candidats traduisait avant tout une volonté d'éliminer ceux qui étaient désapprouvés. Par ailleurs, l'addition des voix recueillies par les réformateurs et les modérés, 16,5 millions de votes et $59 \%$ des voix exprimées, dessinait une carte électorale à peu près similaire à celle de la présidentielle de 2001 lorsque Khâtami, candidat des réformateurs, l'avait emporté haut la main. Dans 194 départements sur 254 , soit $76 \%$, dont une grande majorité située dans les régions périphériques, de $50 \%$ à $92 \%$ des électeurs leur avaient apporté leurs suffrages. La permanence de la géographie électorale des réformateurs s'en trouvant confirmée ; c'est surtout la multiplication des candidatures qui avait entraîné une atomisation du vote réformateur (cf. carte 4).

\section{PRÉSIDENTIELLE DU 12 JUIN DE 2009 : LA FRAUDE MASSIVE}

Quatre candidats allaient entrer en lice à la présidentielle de juin $2009{ }^{20}$. Deux fondamentalistes : Mahmoud Ahmadinejâd, président sortant, et Mohsen Rezầi, ex-commandant en chef des pâsdârân de 1981 à 1997, depuis secrétaire du Conseil de discernement de l'intérêt supérieur du régime ; un réformateur : Mehdi Karoubi : Mir-Hoseyn Moussavi, ex-Premier ministre (1981-1989) qui se présentait officiellement comme " indépendant " mais dont la candidature était clairement soutenue par une partie des réformateurs (tendance dite modérée) et des modérés.

Compte tenu des résultats du premier tour de la présidentielle de 2005, on s'attendait logiquement à ce qu'en 2009 Ahmadinejâd et Rezẩi se fussent partagé les régions supposées " acquises" par les fondamentalistes. Or, l'examen de la carte électorale d'Ahmadinejâd en juin 2009 va dans un tout autre sens. À en croire les résultats proclamés par le ministère iranien de l'Intérieur, Ahmadinejâd aurait attiré

20. Il importe de rappeler que sur 475 inscrits le Conseil de surveillance n'avait validé que quatre candidatures. 
sur sa personne non seulement tous les votes « fondamentalistes " dans les régions "acquises ", mais il aurait aussi multiplié son score par un coefficient allant de 1,1 à 8 selon les départements ${ }^{21}$. Ainsi, Rezâi, l'ex-commandant en chef des pâsdârân, n'aurait pas bénéficié du moindre soutien des réseaux formés par ces mêmes pâsdârân à l'intérieur de ces régions ; il n'aurait recueilli en tout et pour tout qu'un peu plus de 650000 votes, notamment dans la région d'où il est originaire (Sud-Ouest). Alors que le candidat semblait implicitement soutenu par les adversaires d'Ahmadinejâd, Lârijâni et Qâlibâf ; car même si une rivalité entre ces trois personnalités n'était pas exclue, ils avaient adopté la même ligne contre le gouvernement précédent et s'étaient certainement mis d'accord ; compte tenu du score des deux autres au premier tour de 2005 et bien que Rezâi i ne bénéficiât pas d'une même popularité, un résultat honorable était ici attendu (cf. cartes 5 et 6 ).

Mieux : Ahmadinejâd aurait amplifié son espace électoral en grignotant les voix des deux candidats soutenus par les factions des réformateurs et des modérés. Il semble qu'il avait même réussi à inverser la tendance dans une grande partie des régions périphériques qui avaient quatre années plus tôt massivement apporté leurs suffrages aux réformateurs et aux modérés lors du premier tour des présidentielles. Le comportement électoral de ces électeurs était resté pratiquement stable jusqu'au scrutin de 2008 lors duquel la majorité d'entre eux avaient voté pour les réformateurs ou bien des candidats indépendants, en tout cas contre le courant politique soutenu par Ahamdinejâd. Dans la mesure où rien de particulier ne s'était produit entre avril 2008 (second tour des législatives) et juin 2009 qui aurait pu laisser présager un retournement décisif de tendance dans ces régions, on ne voit pas par quel miracle politique Ahmadinejâd a pu y siphonner les voix des réformateurs et des modérés. Compte tenu des falsifications des résultats aux municipales de 2006 et en particulier aux législatives de 2008, il est certain qu'en juin 2009 Ahmadinejâd et ses lieutenants n'ont pu l'emporter dans ces régions que par des manœuvres frauduleuses.

Toujours selon les chiffres officiels, Mahmoud Ahmadinejâd l'aurait emporté dans 185 départements (soit $73 \%$ des 254 départements) en y multipliant ses voix par un coefficient allant de 1,1 à 6 , selon le département. D'après ces résultats, plus de 24 millions d'électeurs, $63 \%$, auraient accordé leurs voix à Ahmadinejâd. Il serait arrivé en tête dans 28 provinces sur 30 et aurait fait aussi bien que Khatami en 1997 et en 2001 ; à cette différence près que l'ex-président de la République, lui, bénéficiait réellement d'un très large soutien populaire.

Deux uniques provinces auraient résisté à la " conquête électorale " d'Ahmadinejâd au profit de Moussavi (cf. carte $\mathrm{n}^{\circ} 7$ ), il s'agit de l'Azerbaïdjan occidental (Nord-Ouest) et du Sistan \& Baloutchistan (Sud-Est), ceci alors que le candidat, originaire de l'Azerbaïdjan oriental, devait plutôt l'emporter dans cette province. La

21. Ce score baissant seulement dans quelques départements de la province de Yazd (Centre) par rapport au scrutin de 2005. 
carte électorale de Moussavi produisant une photographie inversée de celle d'Ahmadinejâd comme si on en était déjà au second tour du scrutin avec en lice deux candidats restants. En effet, parmi les trois rivaux électoraux d'Ahmadinejâd, seul Moussavi paraissait avoir réussi à attirer sur sa personne dans la majorité des départements de 25 à $30 \%$ des voix pour remporter au total un peu plus de 13 millions de votes, $34 \%$ des suffrages exprimés. Le score réalisé par l'ex-Premier ministre relevait cependant en soi plutôt de l'exploit dans la mesure où , absent pendant vingt ans de la scène politique iranienne, il n'avait fait que très tardivement acte de candidature et n'avait disposé que d'un mois pour préparer sa campagne.

Tout s'était passé comme si les architectes de la fraude avaient considéré Moussavi comme le bon adversaire face à Ahmadinejâd et distribué entre ces deux candidats la quasi-totalité des suffrages exprimés à partir de la carte électorale du second tour des présidentielles de juin 2005 d'Ahmadinejâd (cf. carte n ${ }^{\circ} 8$ ). Une carte très proche de celle de juin 2009 de Mahmoud Ahmadinejâd, sauf que lors de ce dernier scrutin ce dernier était censé avoir multiplié ses voix par un coefficient allant de 1,1 à 6 dans les régions périphériques du Nord-Est, Sud, Sud-Est, Sud-Ouest et à l'inverse avoir perdu des voix dans certains départements du Nord-Ouest et du Centre.

Des résultats tout simplement contestables. Inutile de rappeler que le 12 juin 2009, M. Ahmadinejâd se trouvait confronté à trois adversaires de poids, bénéficiant chacun de soutiens considérables qui leur permettaient de réaliser au moins des scores honorables. Or, l'examen de la carte électorale de Mehdi Karoubi met en évidence des anomalies extravagantes (cf. carte $\mathrm{n}^{\circ} 9$ ). Ce dernier qui avait recueilli un peu plus de 5 millions de voix au premier tour de la présidentielle de 2005 alors que sa candidature était investie seulement par l'Association des religieux combattants (l'une des formations issues de la faction des réformateurs) fut le premier à faire officiellement acte de candidature à la présidentielle, pratiquement un an avant le scrutin. Au lendemain de son échec électoral de 2005, il avait formé son parti de « La confiance nationale » et créé un quotidien du même nom afin de s'implanter plus largement dans le pays. En juin 2009, il bénéficiait, outre sa formation politique, du soutien d'une partie des réformateurs (tendance dite radicale) mais aussi de celui de la plus importante confédération estudiantine, le Bureau de la consolidation de l'unité ${ }^{22}$. Il devait en bonne logique au moins améliorer son score par rapport à 2005. Alors qu'il n'allait à la surprise générale recueillir qu'un peu plus de 300000 de voix. Même sa ville natale lui aurait échappé. À croire ces résultats, l'électorat de Karoubi, en dépit de ses quatre années d'efforts et de préparation, lui aurait tourné le dos pour accorder majoritairement ses voix à Ahmadinejâd. Jamais le comportement électoral n'évolue de manière aussi radicale. Et ce alors que les élections municipales de 2006 et les législatives de 2008 avaient confirmé la permanence des tendances électorales dans ces régions au détriment du courant politique représenté 
par Ahmadinejâd. De surcroît, la participation massive de l'électorat réformateur à ce scrutin devait en toute logique tourner à l'avantage des deux candidats soutenus par les réformateurs. Le ministère de l'Intérieur a eu beau se réjouir du taux élevé de la participation au scrutin, il semble avoir truqué les suffrages en faveur d'Ahmadinejâd ${ }^{23}$. Il faut aussi souligner que d'après le ministère de l'Intérieur 46,2 millions d'Iraniens étaient en âge de voter en juin 2009, tandis que selon nos propres estimations, basée sur le recensement iranien de 2006, le nombre d'électeurs se serait élevé à 51,3 millions, soit un écart de 5 millions. Le ministère de l'Intérieur avait sans doute décompté 5 millions de voix pour Ahmadinejâd avant même l'ouverture officielle de la campagne. Les partisans d'Ahmadinejâd n'allaient-ils pas déclarer euxmêmes que ce genre de manœuvre n'était pas une première ? Et le quotidien Keyhân ne révélait-il pas dans son éditorial du 19 août 2008 que les basiji avaient été des " fabricants de votes" (rảy sâzân), qu'ils avaient joué un rôle primordial dans l'élection d'Ahmadinejâd en $2005^{24}$.

Autant d'indices qui donnent légitimement à penser que pour parvenir à une telle issue du scrutin, le gouvernement avait dû mobiliser tous les moyens à sa disposition et entreprendre toutes les manœuvres possibles et imaginables pour trafiquer et truquer le scrutin.

\section{CONCLUSION}

En République islamique, les élections ont toujours été entachées de fraudes et d'irrégularités dont les ampleurs variaient en fonction du type de scrutin et des enjeux politiques. Le scrutin de 2009 représentait à l'évidence des enjeux politiques d'importance pour des raisons liées à la fois au contexte politique interne, extrêmement tendu, et au contentieux entre la République islamique et les puissances occidentales autour notamment du programme nucléaire. Pour l'aile la plus radicale des fondamentalistes incarnée par Mahmoud Ahmadinejâd, la réélection de ce dernier était nécessaire afin d'affirmer son hégémonie au sein de la faction et de poursuivre du même coup ses projets politiques engagés en 2003 et mis en œuvre depuis l'élection d'Ahmadinejâd à la présidence de la République en 2005. Étant donné cependant un mécontentement passablement généralisé, notamment au sein des couches moyennes urbaines, et en particulier chez les jeunes et les femmes, Ahmadinejâd n'était nullement assuré de sa réélection. Un mécontentement qui s'était d'ailleurs clairement exprimé à deux reprises à l'occasion des élections municipales de 2006 et des législatives de 2008. Compte tenu de ce contexte et surtout de la mobilisation exceptionnelle de l'électorat « réformateur » lors du scrutin de juin 2009, il était tout

23. Il n'existe pas en Iran de bulletins de vote imprimés au nom des candidats ; c'est à chaque électeur d'inscrire sur le bulletin le nom du candidat pour lequel il souhaite voter.

24. Keyhân, 19 août 2008. 
simplement impossible que Mahmoud Ahmadinejâd, président sortant, puisse l'emporter haut la main ; il a donc fallu que le président sortant et ses partisans recourent à des mécanismes et dispositifs divers et variés qui allaient lui permettre d'obtenir le résultat qu'on sait. 
Carte 1 Suffrages recueillis par Mahmoud Ahmadinejâd au premier tour des présidentielles de juin 2005
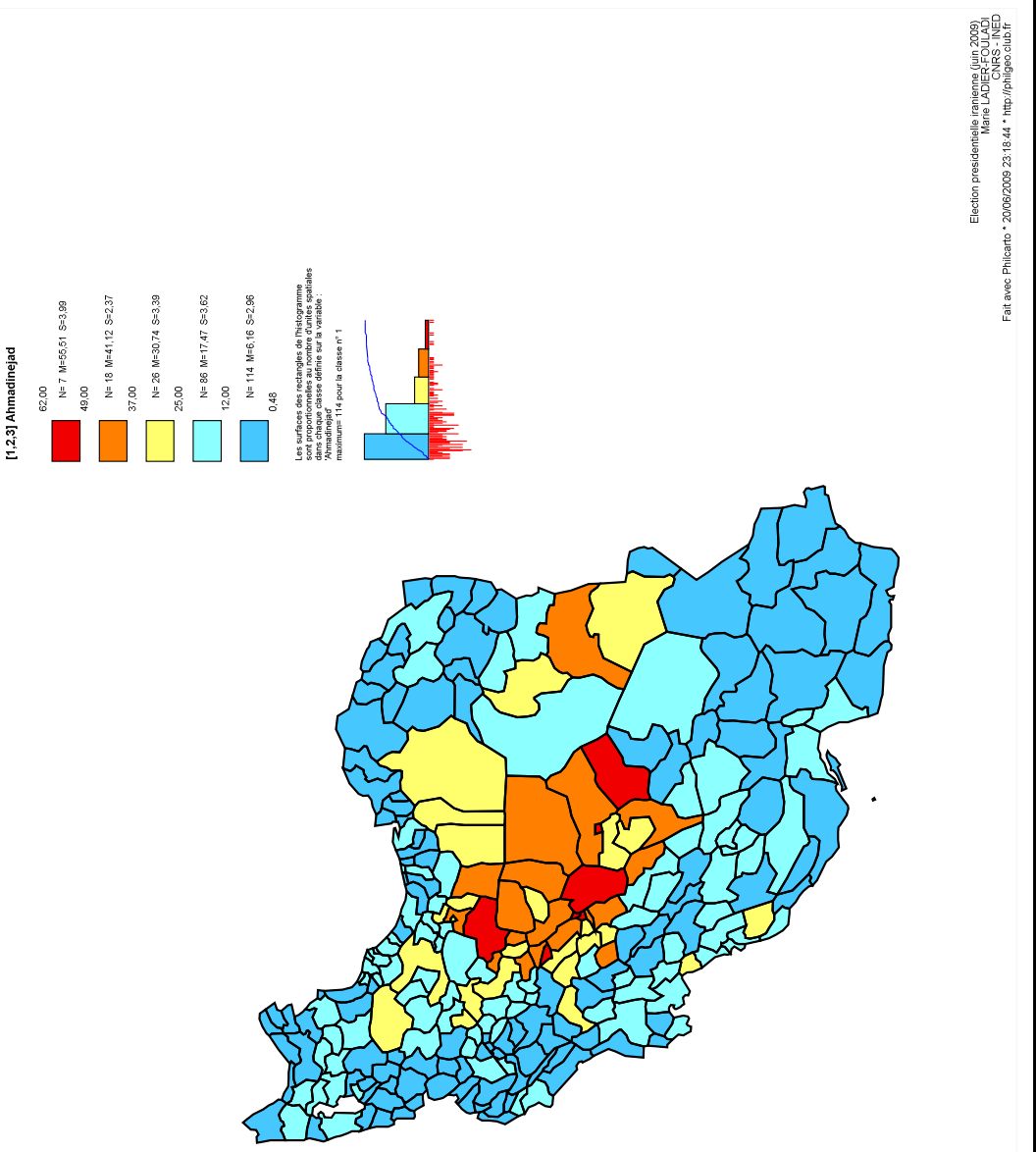


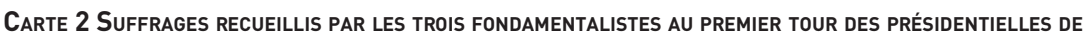
JUIN 2005

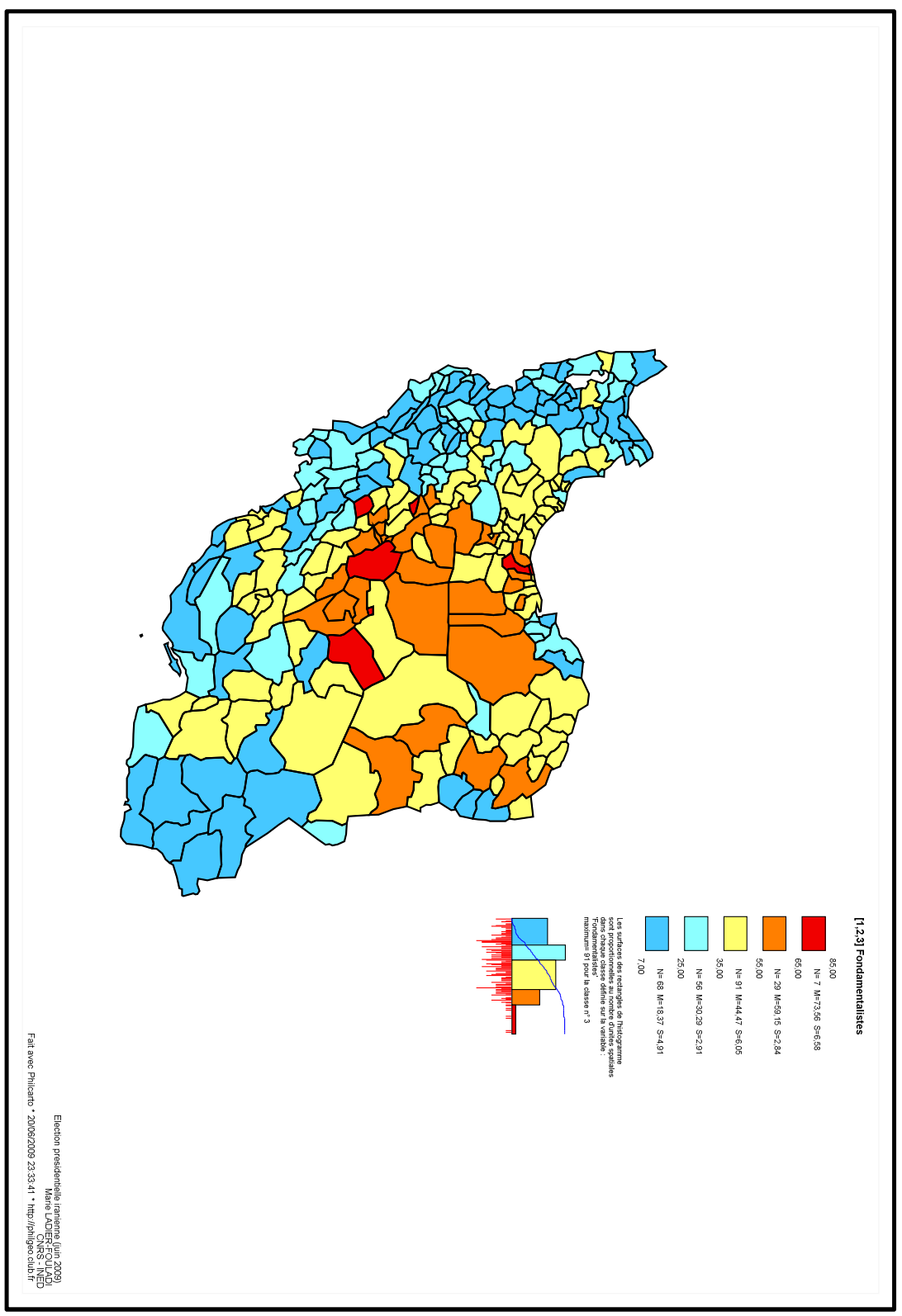



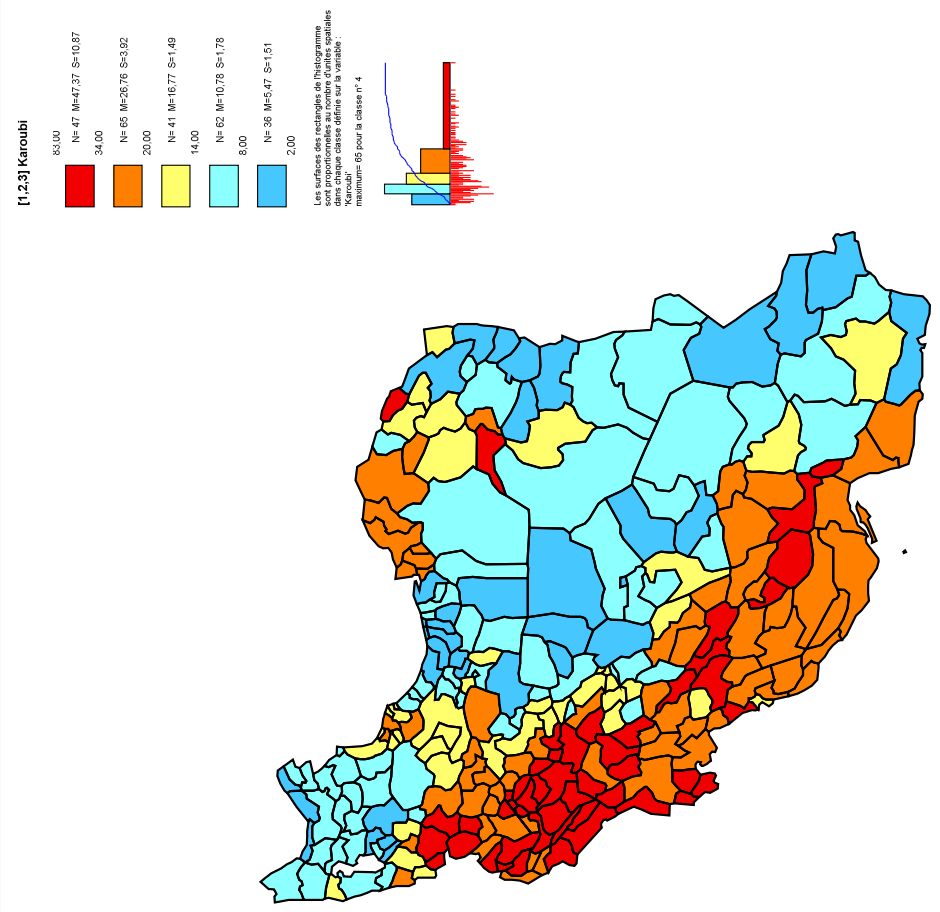
Carte 4 Suffrages recueillis par les réformateurs et Hâshemi Rafsanjâni au premier tour des PRÉSIDENTIELLES DE JUIN 2005
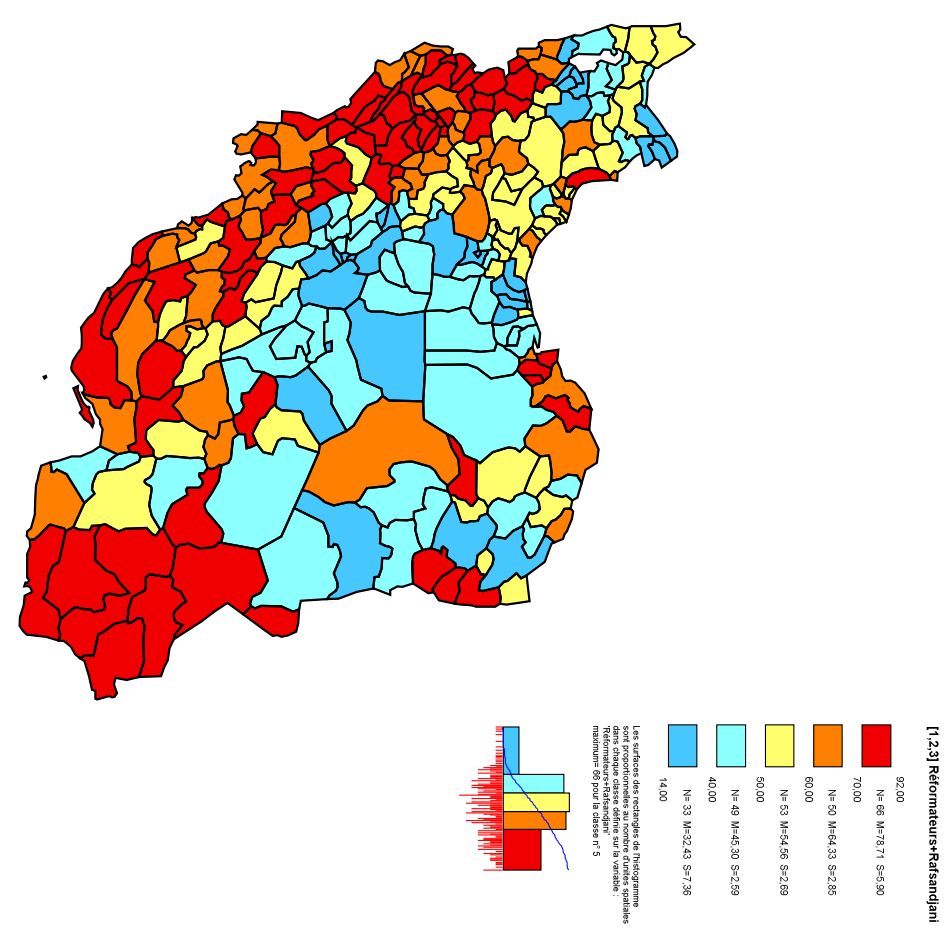


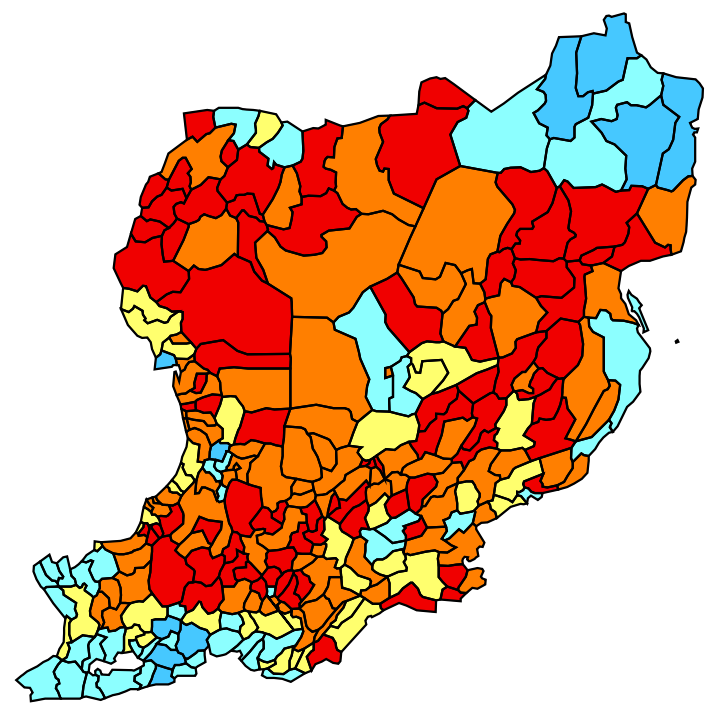


Carte 6 Suffrages recueillis Par Mohsen RezầI au Premier tour des Présidentielles de JuIn 2009

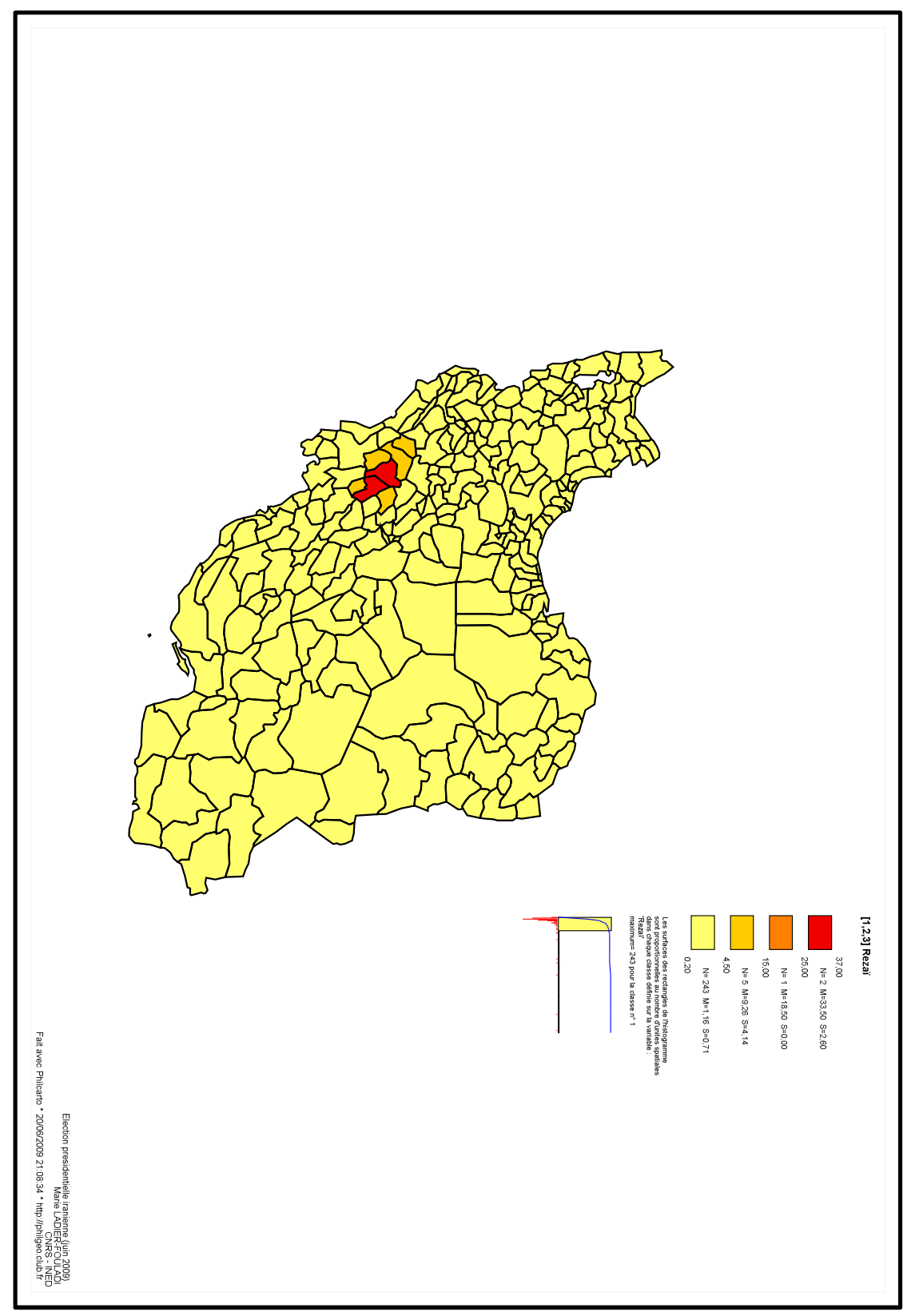



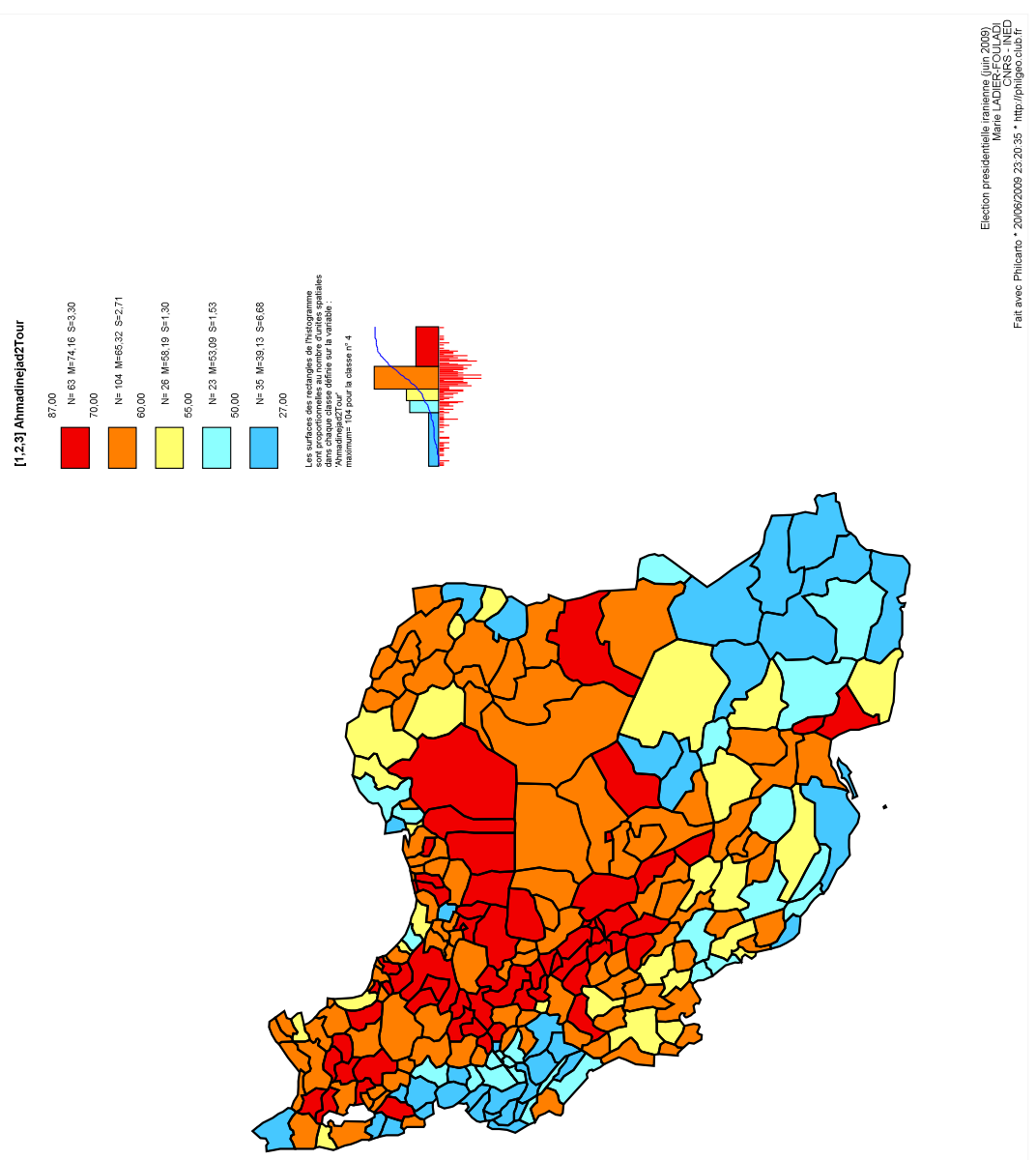


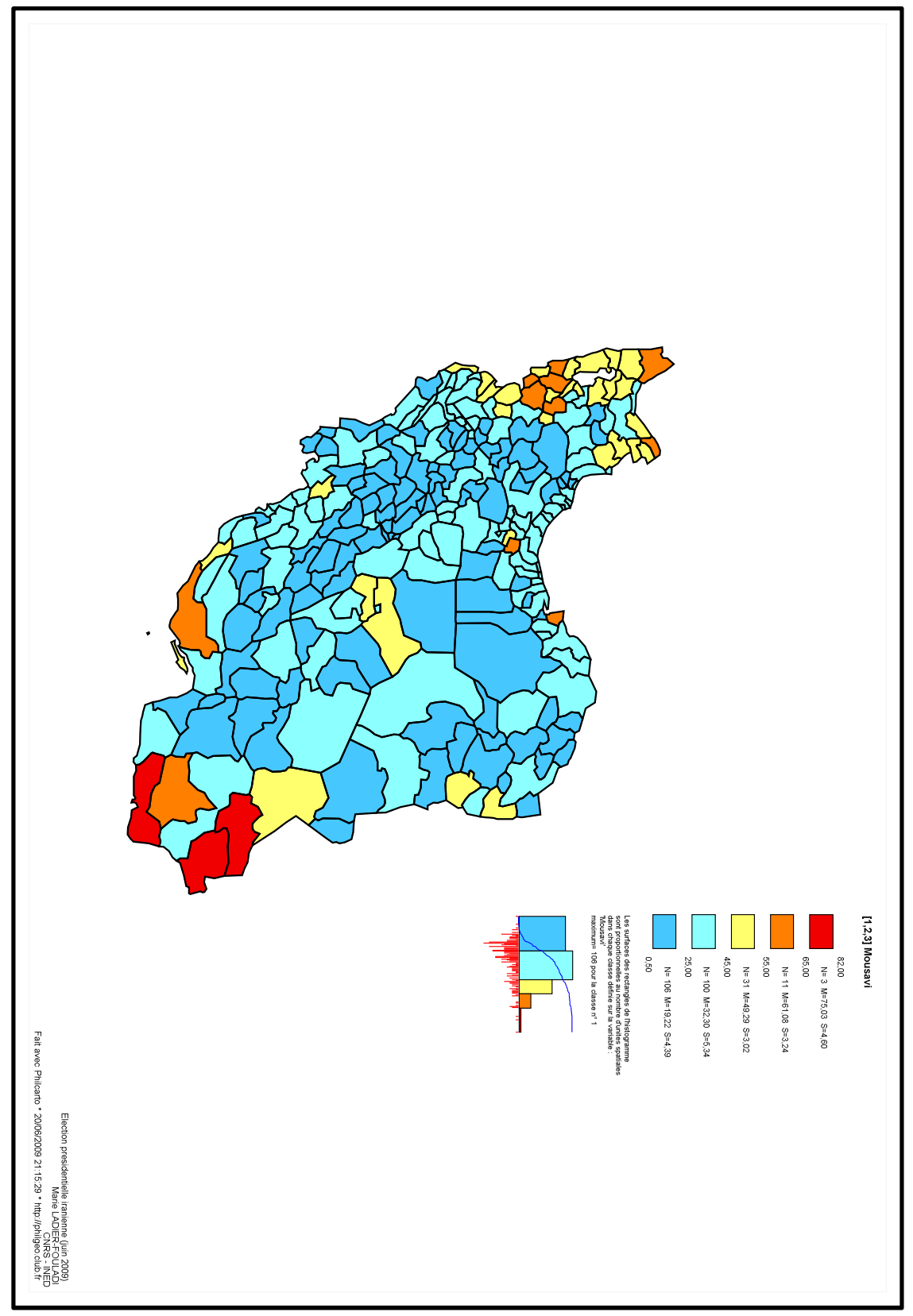


Carte 9 Suffrages recueillis par Mehdi Karoubi À la présidentielle de Juin 2009

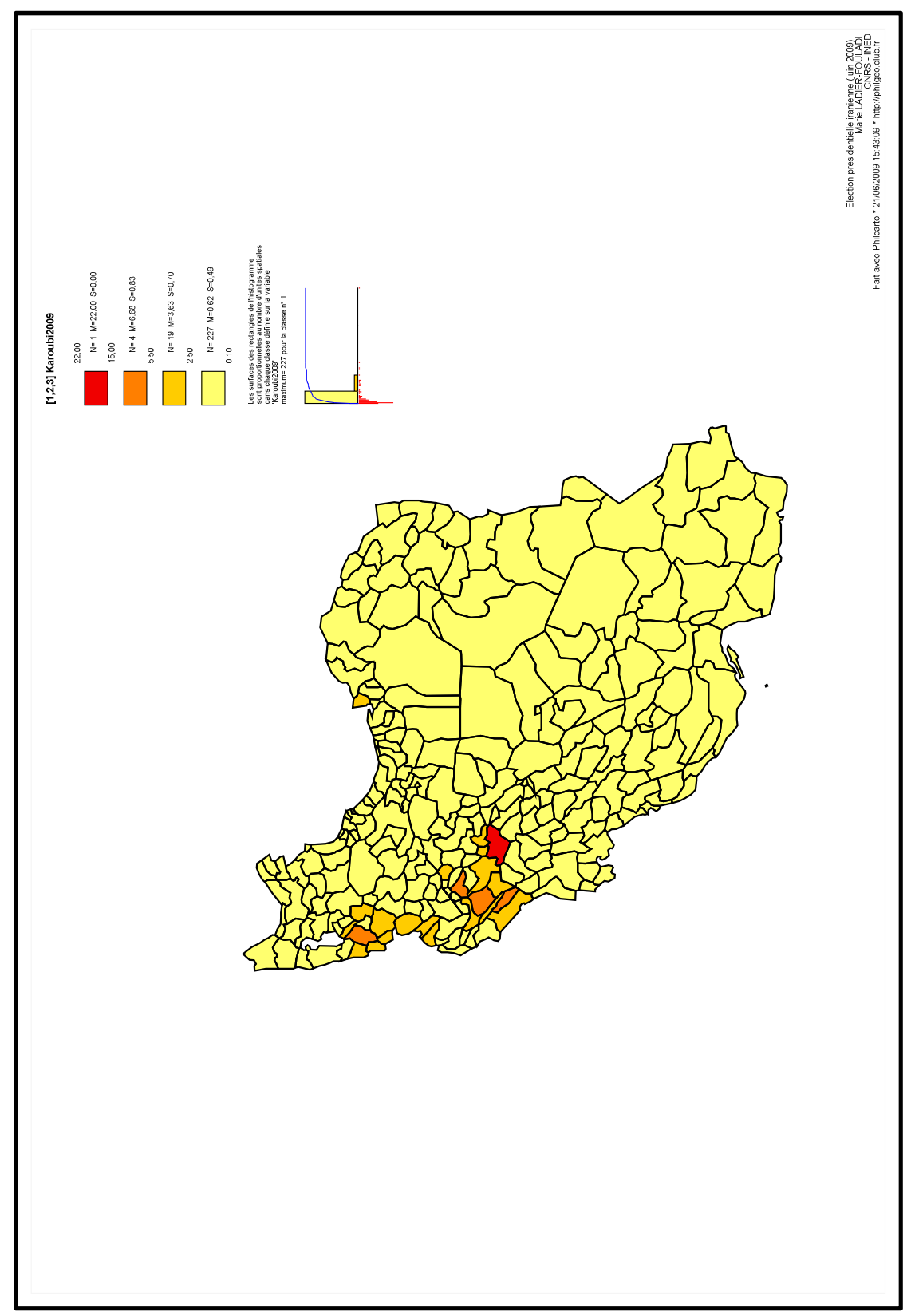

